\title{
Illumining phase transformation dynamics of vanadium oxide cathode by multimodal techniques under operando conditions
}

\author{
Guobin Zhang ${ }^{1, \S}$, Tengfei Xiong ${ }^{1, \S}$, Xuelei Pan ${ }^{1}$, Yunlong Zhao ${ }^{2,3}(\varangle)$, Mengyu Yan $^{4}(\varangle)$, Haining Zhang ${ }^{1}, B{ }^{2}$ ke $W^{1}$, \\ Kangning Zhao ${ }^{1}$, and Liqiang $\mathrm{Mai}^{1}(\bowtie)$ \\ ${ }^{1}$ State Key Laboratory of Advanced Technology for Materials, Synthesis and Processing, International School of Materials Science and Engineering, Wuhan \\ University of Technology, Wuhan 430070, China \\ ${ }^{2}$ Advanced Technology Institute, University of Surrey, Guildford GU2 7XH, UK \\ ${ }^{3}$ National Physical Laboratory, Teddington TW11 OLW, UK \\ ${ }^{4}$ Materials Science and Engineering Department, University of Washington, Seattle, WA 98195-2120, USA \\ ${ }^{\S}$ Guobin Zhang and Tengfei Xiong contributed equally to this work.
}

(C) The Author(s) 2019

Received: 8 November 2018 / Revised: 21 January 2019 / Accepted: 29 January 2019

\begin{abstract}
Subtle structural changes during electrochemical processes often relate to the degradation of electrode materials. Characterizing the minutevariations in complementary aspects such as crystal structure, chemical bonds, and electron/ion conductivity will give an in-depth understanding on the reaction mechanism of electrode materials, as well as revealing pathways for optimization. Here, vanadium pentoxide $\left(\mathrm{V}_{2} \mathrm{O}_{5}\right)$, a typical cathode material suffering from severe capacity decay during cycling, is characterized by in-situ X-ray diffraction (XRD) and in-situ Raman spectroscopy combined with electrochemical tests. The phase transitions of $\mathrm{V}_{2} \mathrm{O}_{5}$ within the $0-1 \mathrm{Li} / \mathrm{V}$ ratio are characterized in detail. The $\mathrm{V}-\mathrm{O}$ and $\mathrm{V}-\mathrm{V}$ distances became more extended and shrank compared to the original ones after charge/discharge process, respectively. Combined with electrochemical tests, these variations are vital to the crystal structure cracking, which is linked with capacity fading. This work demonstrates that chemical bond changes between the transition metal and oxygen upon cycling serve as the origin of the capacity fading.
\end{abstract}

\section{KEYWORDS}

in-situ X-ray diffraction (XRD), in-situ Raman, electrochemical process, phase transformation.

\section{Introduction}

Lithium-ion batteries have been widely developed to meet the increasing demands of energy applications, such as electric vehicles and electrical storage from wind to solar power $[1,2]$. However, lithium-ion batteries fall short of the ever-increasing energy density demands regarding the desirable range of electric vehicles and battery life of portable electric devices [3, 4]. Among battery components, the cathode material is one of the main limitations to desired energy densities [5]. While most commercial electrode materials fall short of aspirations, materials in multi-electron reaction systems (such as $\mathrm{MoO}_{3}, \mathrm{~V}_{2} \mathrm{O}_{5}$, and $\mathrm{CuF}_{2}$, among which $\mathrm{V}_{2} \mathrm{O}_{5}$ is one of the best candidates) have received significant interest for their higher capacity [6-11]. These materials, with enough space to store more than one lithium per formula unit, however, suffer from poor structural stability. To overcome this issue, understanding the structural evolution during the electrochemical process is crucial [12]. Thus, various tools have been used to investigate the degradation mechanism, which is helpful to optimize these cathode materials further. Among these tools, in-situ X-ray diffraction (XRD) has been demonstrated to be a powerful tool for exploring the structural evolution in the electrochemical field [13]. Unsatisfactorily, it failed to unfold the chemical bond changes of the cathode, which usually happens in multi-electron systems [14]. Luckily, Raman spectroscopy is very sensitive to alternations of bonding and X-ray absorption fine spectroscopy (XAFS) (including X-ray absorption near edge structure
(XANES) and extended X-ray absorption fine structure (EXAFS)) is powerful in detecting of bond length, both of which are important supplements to XRD analysis [15].

Therefore, these tools are very suitable for investigating the multi-electron reaction system if we can cross-check the proposed mechanism by combining all of them. With accommodation for up to 3 lithium ions, $\mathrm{V}_{2} \mathrm{O}_{5}$ is a very promising cathode material and the biggest problem before commercialization lies in fast capacity fading, which involves structural deformation [16, 17]. Former works showed that during the lithiation process there exist four phases in $\mathrm{Li}_{x} \mathrm{~V}_{2} \mathrm{O}_{5}(0<x \leq 2)$ : $\alpha$ phase where $x \approx 0, \varepsilon$ phase where $x \approx 0.5, \delta$ phase where $x=1$ and $\gamma$ phase where $x=2$ [18]. Cocciantelli and co-authors investigated the electrochemical insertion of lithium ions in the process of $0<x \leq 2$ via ex-situ XRD [19]. Later, they researched on the electrochemical process of $\mathrm{Li}_{x} \mathrm{~V}_{2} \mathrm{O}_{5}$ system while $0<x<1$ in detail using XRD [20]. Pereira-Ramos and co-workers used Raman spectroscopy to study the lithium insertion into $\mathrm{V}_{2} \mathrm{O}_{5}$ and provided insight into the chemical changes [21, 22]. To get more specific information, Mansour employed in-situ XAFS to study the electrochemical process of $\mathrm{V}_{2} \mathrm{O}_{5}$ and found that $\mathrm{V}-\mathrm{O}$ chemical bonds play a vital role during the electrochemical reaction [23]. However, very few works focused on the combination of operando Raman spectroscopy and X-ray diffraction in tracing the hidden reason for capacity fading at high lithium insertion concentrations [24]. Also, former works attributed the capacity fading to the V-O layer puckering, where further understanding of the crystal evolution 
is desired [25]. It is of importance in understanding the reaction process of vanadium oxide, thus will enlarge its usage in the electrochemical field $[9,10]$.

Given all that above, a combination of in-situ XRD, in-situ Raman and $e x$-situ XAFS is utilized in this work to investigate the intrinsic reason for capacity fading of the multi-electron reaction system and $\mathrm{V}_{2} \mathrm{O}_{5}$ is taken as a model. The in-situ Raman results show that the shortest $\mathrm{V}-\mathrm{O}$ bond variations are responsible for the crystal structure destruction. The ex-situ XAFS results coincide with the Raman and XRD tests and find that the $\mathrm{V}-\mathrm{V}$ bond, which is the skeleton of the crystal, is essential in the crystal structure. Further in-situ electrochemical impedance spectroscopy (EIS) tests reveal the chemical kinetics during lithium insertion into $\mathrm{V}_{2} \mathrm{O}_{5}$ crystal. This work indicates that the breaking of the metal-oxygen and metal-metal bonds may be the origin of the capacity fading.

\section{Experimental}

\subsection{Material synthesis}

The $\mathrm{V}_{2} \mathrm{O}_{5}$ nanowire was synthesized by a hydrothermal method. $0.72 \mathrm{~g} \mathrm{~V}_{2} \mathrm{O}_{5}$ powder was added into $60 \mathrm{~mL}$ deionized water and stirred vigorously at room temperature, then $0.3 \mathrm{~g}$ polyethylene glycol was added to this homogeneous solution and continuously stirred for $2 \mathrm{~h}$ until a transparent orange solution was obtained. The resultant solution was then sealed into an $80 \mathrm{~mL}$ autoclave and hydrothermally treated at $180^{\circ} \mathrm{C}$ for 2 days, followed by precipitated isolation and washed with anhydrous ethanol and deionized water several times. Finally, it was dried at $70{ }^{\circ} \mathrm{C}$ in the vacuum for $24 \mathrm{~h}$ and then annealed at $350{ }^{\circ} \mathrm{C}$ for $2 \mathrm{~h}$ in air.

\subsection{Material characterizations}

XRD measurements were performed to investigate the crystallographic information using a Bruker D8 Discover X-ray diffractometer with a non-monochromatic $\mathrm{Cu} \mathrm{K} \alpha \mathrm{X}$-ray source. Raman spectra were collected using Horiba HR Evolution with $532 \mathrm{~nm}$ line from the He-Ne laser. Transmission electron microscopy (TEM) images and high-resolution TEM (HRTEM) images were recorded by a JEOL JEM-2100F FEF TEM. Hard X-ray experiments were carried out at the $4 \mathrm{~W} 1 \mathrm{~B}$ beamline in the Beijing Synchrotron Radiation Facility (BSRF) and the $E_{0}$ is corrected with the vanadium foil. The $\mathrm{V} \mathrm{K}$ edge $E_{0}$ was $5,469 \mathrm{eV}$ and the normalization order is third. Rbkg and k-weight are 1.0 and 2.0, respectively. XANES spectra were normalized to an edge jump of unity taking into account the atomic background after the edge as revealed from the EXAFS analysis. A prior removal of the background absorption was done by subtraction of a linear function extrapolated from the pre-edge region.

For in-situ XRD measurement, the electrode was placed right behind an X-ray-transparent beryllium window, which also acted as a current collector. The in-situ XRD signals were collected using the planar detector in still mode during the discharge/charge process, and each pattern took $1 \mathrm{~min}$ to acquire. In order to allow penetration of the Raman laser, aluminum foil with a hollow of $3 \mathrm{~mm}$ in diameter was used as the current collector. The white sapphire as thick as $0.05 \mathrm{~mm}$ with the Raman laser transmittance of $90 \%$ served as the window. The power for collecting Raman spectrum was $10 \%$ of the total power of $532 \mathrm{~nm} \mathrm{He}-\mathrm{Ne}$ laser to avoid burning the cathode. In order to reduce background interference and cosmic ray interference, we use two exposures to obtain each spectrum, each time is $15 \mathrm{~s}$, so each spectrum takes $30 \mathrm{~s}$ to obtain.

Staircase potentio electrochemical impedance spectroscopy (SPEIS) was started from 4.0 to $2.0 \mathrm{~V}$ during the anodic process. The SPEIS tests the successive impedance spectra during the voltage scans thus to investigate the reaction kinetics. The number of potential steps was 160 and the wait time for each potential step was $30 \mathrm{~min}$. The voltage sinus amplitude was $10 \mathrm{mV}$, the frequency range was
$0.01-100,000 \mathrm{~Hz}$ and the number of frequency points per decade in linear spacing was 10 , where 71 points were collected for one EIS spectrum.

\section{Result and discussion}

TOPAS 4.2 was introduced to implement the Rietveld refinement of the acquired XRD pattern of $\mathrm{V}_{2} \mathrm{O}_{5}$ in Fig. 1(a). The calculated result shows that the space group of the as-prepared sample is Pmn21 with Bragg parameters of $a=11.5 \AA, b=4.37 \AA$, and $c=3.56 \AA$. These cell parameters and atomic coordinates for the $\mathrm{V}_{2} \mathrm{O}_{5}$ are given in Tables S1 and S2 in the Electronic Supplementary Material (ESM), respectively. The refined result shows that the sample is in perfect shape of the orthorhombic and that no other phase is observed. The three different $\mathrm{V}-\mathrm{O}$ distances, according to the refined XRD data, are listed in Fig. S1 in the ESM. The Raman spectrum of the pristine sample is shown in Fig. 1(b) and all the vibration bands are well assigned to $\mathrm{V}_{2} \mathrm{O}_{5}$ according to the literature. The vibration of the shortest $\mathrm{V}-\mathrm{O}$ bond in the $b$-axis can be assigned to the Raman band at $980 \mathrm{~cm}^{-1}$ [26].

To investigate the phase transition in the shallow lithium insertion process, in situ XRD within the voltage windows of 3.2-4.0 and 2.8-4.0 V corresponding to half and one lithium per $\mathrm{V}_{2} \mathrm{O}_{5}$ formula unit, respectively, was conducted as shown in Fig. 2. Two-dimensional image of the XRD patterns were drawn to get a clear understanding of the phase evolution process, where the intensity is defined by the colors shown in the scale bar on the right. Due to the self-adaption effect, the electrochemical process started from the charging process to get the inserted lithium out of the crystal $[18,20]$.
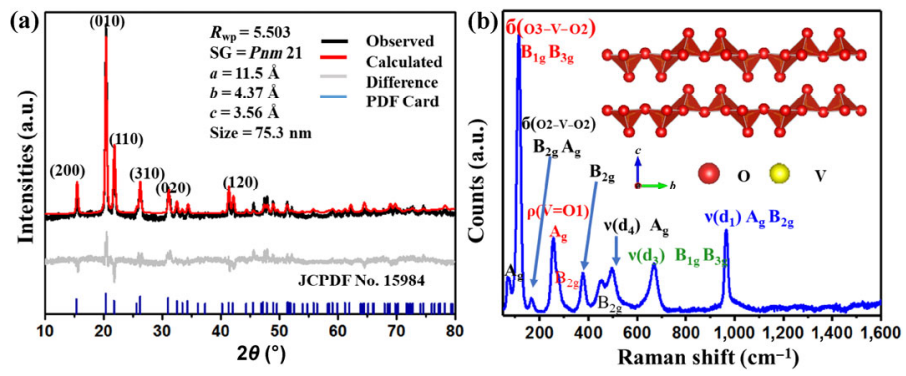

Figure 1 (a) Rietveld refinement of the XRD pattern and (b) Raman spectrum of $\mathrm{V}_{2} \mathrm{O}_{5}$ nanowire.
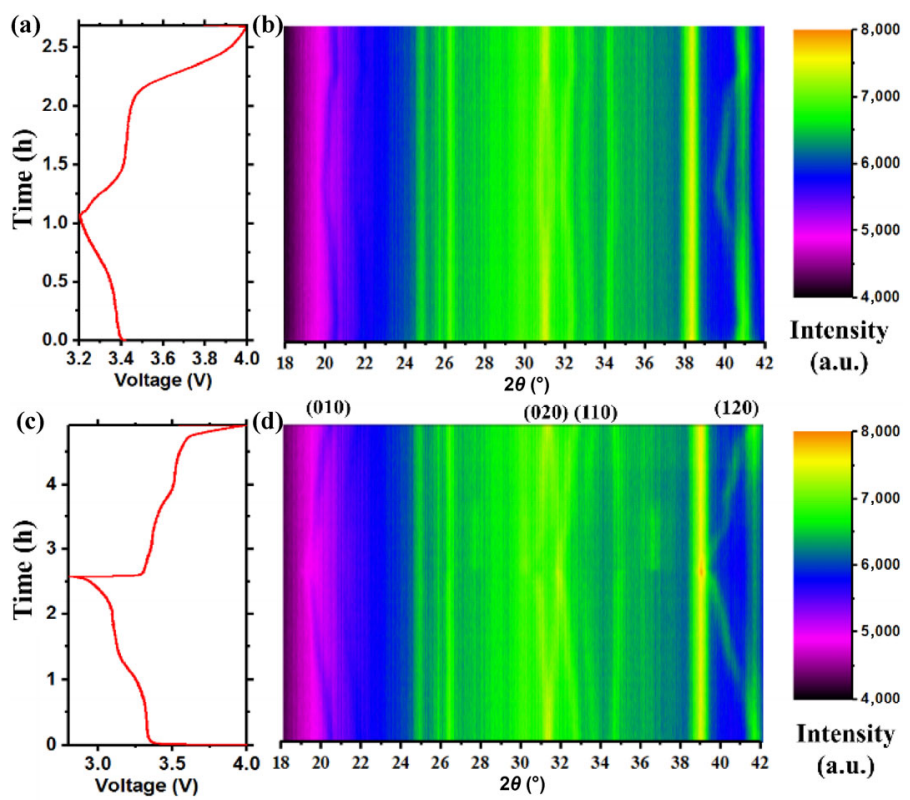

Figure 2 In-situ XRD patterns of $\mathrm{V}_{2} \mathrm{O}_{5}$ in the voltage windows of 3.2-4.0 and $2.8-4.0 \mathrm{~V}$ at a current density of $50 \mathrm{~mA} \cdot \mathrm{g}^{-1}$. 
The galvanostatic charge-discharge curve in Fig. 2(a) presents one voltage plateau during charge and discharge, which indicates the $a$ phase transformation to the $\varepsilon$ one, which is a reversible reaction. Two theta angle region of $18^{\circ}-42^{\circ}$ is selected, which includes the prominent lattice planes of (010), (020), (110) and (120). By observing the changes of four crystal planes, the lattice parameters $a, b$ and their changes during the reaction can be obtained. In Fig. 2(b), the diffraction peak at $23^{\circ}$ gradually shifts to lower angle with negligible breaks, while the (010) lattice planes shift to lower angle but jump to its lower angle at $20.5^{\circ}$ with breaks observed. This means while lithium inserts into the $\mathrm{V}_{2} \mathrm{O}_{5}$ crystal, it inserts not only in the traditionally $b$ axis but also through $a$ axis. This result indicates there is little difference between the $\alpha$ and $\varepsilon$ phases.

As for the deeper insertion of lithium to one per formula unit, the voltage is widened to $2.8-4.0 \mathrm{~V}$ or $2.4-4.0 \mathrm{~V}$, where two voltage plateaus observed. The phase transition from $\varepsilon$ phase to $\delta$ seems different compared with the previous process. The strong intensity around $23^{\circ}$ shifts to lower angle and becomes less prominent when transformation to $\varepsilon$ phase occurs. The strong peak around $42^{\circ}$ first jumps to the lower angle belonging to the $\varepsilon$ phase and then to $39^{\circ}$ the $\delta$ phase with no intensity break. The in-situ XRD results show that both the phase transitions to $\varepsilon$ and $\delta$ are reversible. The XRD refinement of the $2.4 \mathrm{~V}$ discharge product shown in Fig. S2 in the ESM shows that the $\alpha-\mathrm{V}_{2} \mathrm{O}_{5}$ phase with lattice parameters of $a=$ $11.512 \AA, b=4.371 \AA$ and $c=3.56 \AA$ transformed to $\delta-\mathrm{LiV}_{2} \mathrm{O}_{5}$ with lattice parameters of $a=11.717 \AA, b=4.667 \AA$ and $c=3.58 \AA$. This lithium insertion process causes the $\mathrm{V}_{2} \mathrm{O}_{5}$ crystal to be slightly puckered according to the XRD refinement result.

The chemical bond changes in $\mathrm{V}_{2} \mathrm{O}_{5}$ during the lithium insertion will result in variations in Raman spectra. As shown in Fig. 3(b), for the bonds around 110, 150, 280, 290 and $700 \mathrm{~cm}^{-1}$ the intensity becomes weaker, shifts to a higher position, and then merely disappears. The band variation during charge is the inverse process during discharging. It is worth noting that this phenomenon can be described as the transformation of $\alpha-\mathrm{V}_{2} \mathrm{O}_{5}$ to $\varepsilon-\mathrm{Li}_{0.5} \mathrm{~V}_{2} \mathrm{O}_{5}$, with the weaker vibration. As the deeper lithium insertion $\left(\varepsilon-\mathrm{V}_{2} \mathrm{O}_{5}\right.$ transforms to $\delta-\mathrm{LiV}_{2} \mathrm{O}_{5}$ ), the Raman intensity does not change significantly.

To study the local structure changes with shallow lithium intercalation, in-situ Raman spectroscopy is applied during the

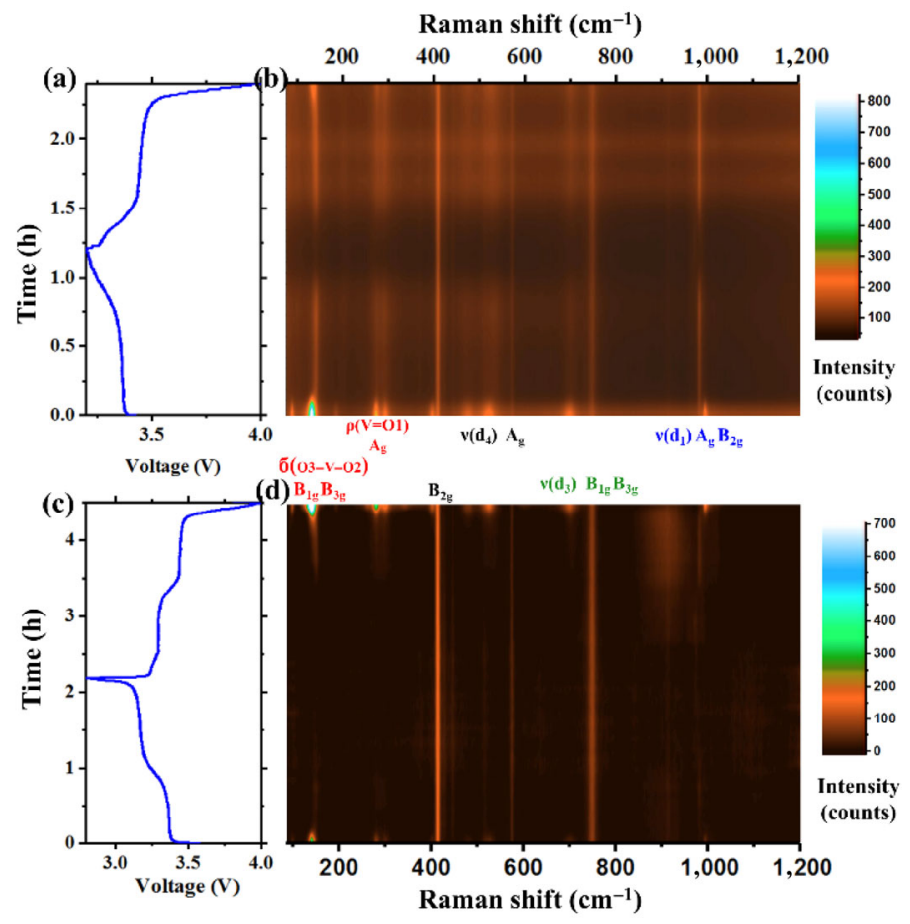

Figure 3 In-situ Raman spectra of $\mathrm{V}_{2} \mathrm{O}_{5}$ within the voltage windows of 3.2-4.0 and $2.8-4.0 \mathrm{~V}$ at a current density of $50 \mathrm{~mA} \cdot \mathrm{g}^{-1}$. electrochemical process. Here, we reinvestigated the powder $\alpha-\mathrm{V}_{2} \mathrm{O}_{5}$, which is the same material used in the in-situ XRD and other tests. The operando Raman measurement results of $\mathrm{V}_{2} \mathrm{O}_{5}$ within the voltage windows of 3.2-4.0 and 2.8-4.0 V are shown in Figs. 3(a) and 3(b), and 3(c) and 3(d), respectively.

Two-dimensional images of the in-situ Raman spectrums are drawn, where the Raman intensity is defined with color and the scale bar presented on the right. The intensities over 810 counts are treated as the same color in Fig. 3(b), while that upper limit is 705 in Fig. 3(d). The intermediate phase with relatively low Raman intensities during the reaction is not very obvious, and thus an upper limit makes the observation of the signal variation easier.

To further investigate the lithium insertion mechanism, in-situ Raman mapping with a spatial resolution of $1 \mu \mathrm{m}$ was conducted at different electrochemical states of $\mathrm{Li}_{x} \mathrm{~V}_{2} \mathrm{O}_{5}$. There are 3,600 Raman spectra collected at each electrochemical state as shown in Fig. 4. The optical images of $\mathrm{V}_{2} \mathrm{O}_{5}$ at open circuit voltage (OCV) and $2.0 \mathrm{~V}$ discharge state are shown in Figs. S5(a) and S5(b) in the ESM. To characterize the phase evolution process, three band regions are selected in a whole spectrum: Band region that can represent $\mathrm{V}_{2} \mathrm{O}_{5}$ is $110-170 \mathrm{~cm}^{-1}$ and $\mathrm{D}$ and $\mathrm{G}$ bands of carbon are 1,280-1,460 and $1,500-1,700 \mathrm{~cm}^{-1}$, respectively. The colorful images in Fig. 4 are drawn based on the integration of the selected region. It can be seen at OCV that there are three to four high spots, which is due to the uneven surface of the cathode. During the electrochemical process the variations of $B_{1 g} B_{3 g}, D$ and $G$ bands are nearly the same. Upon high lithium insertion to 1 lithium per vanadium, the strong-intensity region tends to be homogenous and weaker, which means the vibration bands in the material disappear.

From the point view of in-situ XRD, the capacity fading may originate from the variations of the $\mathrm{V}-\mathrm{O}$ and $\mathrm{V}-\mathrm{V}$ bonds. However, it is not very clear which of the two is the dominant reason. To resolve this issue, in-situ Raman test at a current density of $100 \mathrm{~mA} \cdot \mathrm{g}^{-1}$ was conducted for 4 cycles within the voltage window of 2.0-4.0 V (Fig. 6). Three noticeable Raman vibration band changes of $\mathrm{V}_{2} \mathrm{O}_{5}$ during the electrochemical process are listed, which represent the $6(\mathrm{O} 3-\mathrm{V}-\mathrm{O} 2), v\left(\mathrm{~d}_{3}\right)$ and $v\left(\mathrm{~d}_{1}\right)$. Figure $6(\mathrm{a})$ presents the peak intensity variations of the three-selected prominent band regions during the electrochemical process. The intensity of the peak decays rapidly with cycling. This indicates that the crystallinity of the local
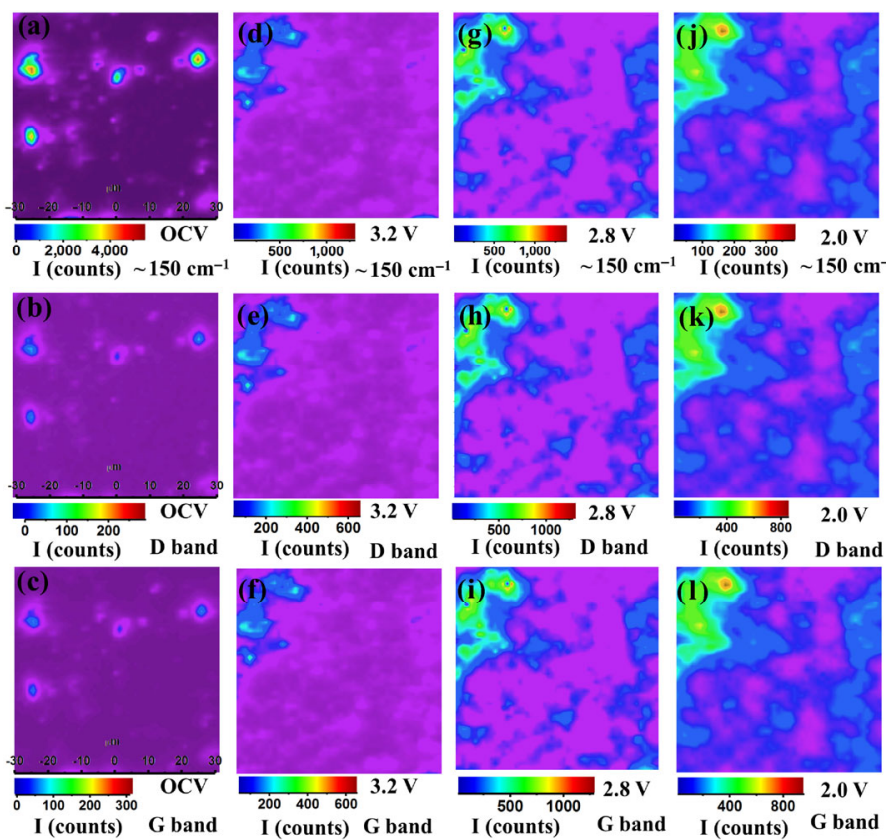

Figure 4 In-situ Raman mapping of electrochemical states of $\mathrm{Li}_{x} \mathrm{~V}_{2} \mathrm{O}_{5}$ : (a)-(c) for OCV, (d)-(f) for discharge to $3.2 \mathrm{~V},(\mathrm{~g})$-(i) for discharge to $2.8 \mathrm{~V}$, (j)-(l) for discharge to $2.0 \mathrm{~V}$. 


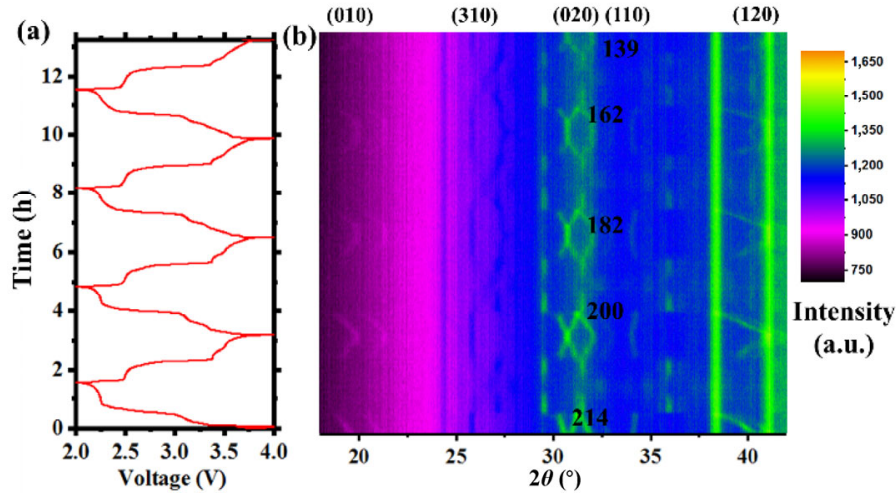

Figure 5 In-situ XRD patterns of $\mathrm{V}_{2} \mathrm{O}_{5}$ in the voltage window of $2.0-4.0 \mathrm{~V}$ for 4 cycles at a current density of $100 \mathrm{~mA} \cdot \mathrm{g}^{-1}$.

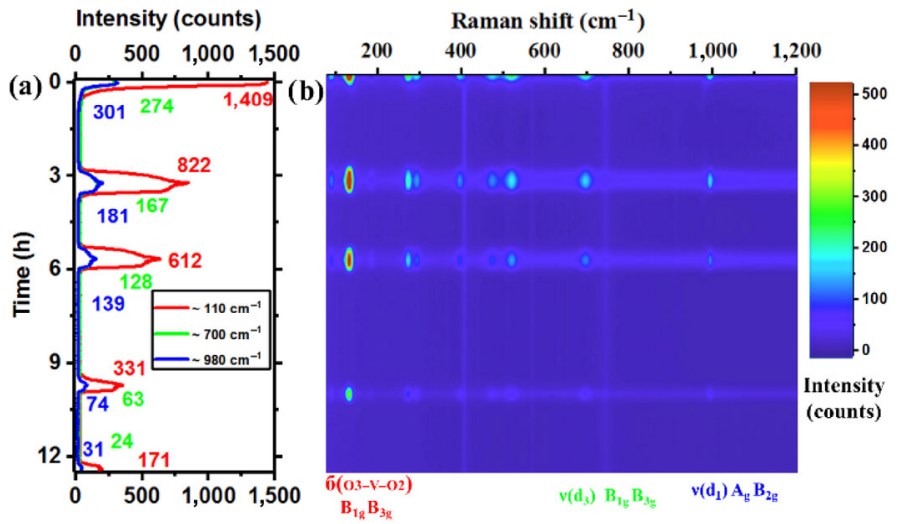

Figure 6 In-situ Raman spectra of $\mathrm{V}_{2} \mathrm{O}_{5}$ in the voltage window of $2.0-4.0 \mathrm{~V}$ for 4 cycles at a current density of $100 \mathrm{~mA} \cdot \mathrm{g}^{-1}$.

structure also decreases, which may relate to the capacity decay. To study the decay, here we fitted the three profiles and the detailed fitting information are shown in Fig. S6 in the ESM. The calculated result of the band around $980 \mathrm{~cm}^{-1}$ fits well with the capacity fading trend, which can be treated as the sign of the capacity fading. Moreover, this Raman band moves towards lower wavenumbers and becomes wider, which means that the shortest $\mathrm{V}-\mathrm{O}$ bond along $b$ axis gets longer and more disordered during cycling.

The SPEIS was tested from 4.0 to $2.0 \mathrm{~V}$. During the electrochemical insertion, the cell is kept still for $30 \mathrm{~min}$ at each potential step of $12.5 \mathrm{mV}$, and then an EIS spectrum is taken. There are 199 EIS results taken as shown in Fig. $7(\mathrm{~b})$. The time is set as the $x$-axis, which represents the lithium insertion amount. $Y$ is the $Z^{\prime}$ in the Nyquist plots, and the $-Z$ " is presented by different colors, which vividly show the variation of $Z^{\prime}$ and $Z$ ". Further, to quantify the EIS results of different degrees of lithium insertion, a series of fittings were done, as shown in Fig. 7(b) [27]. The Nyquist plots were fitted by the two-time constant model (Fig. 7(c) inset) in which two obvious linked semicircles appeared on the complex plane with a looming diffuse control. It is acknowledged that the two semicircles in the high-frequency and middle-frequency regions represent the surface diffusion of $\mathrm{Li}^{+}$and charge transfer process, respectively, and the diffuse control in low-frequency region can be attributed to bulk diffusion of $\mathrm{Li}^{+}$. The values of $R_{\mathrm{s}}$ and $R_{\mathrm{ct}}$ have an opposite change tendency with the lithium intercalation process. When current density increases, $R_{\mathrm{s}}$ and $R_{\mathrm{ct}}$ decrease sharply at the same time. The $R_{\mathrm{s}}$ and $R_{\mathrm{ct}}$ does not change that much during the electrochemical process, which means that the phase transition does not importantly affect the lithium transportation.

XAFS was employed to investigate the detailed structural variation (Fig. 8), and the data analysis has been performed using the ATHENA package, where multiple scattering theory was taken into account
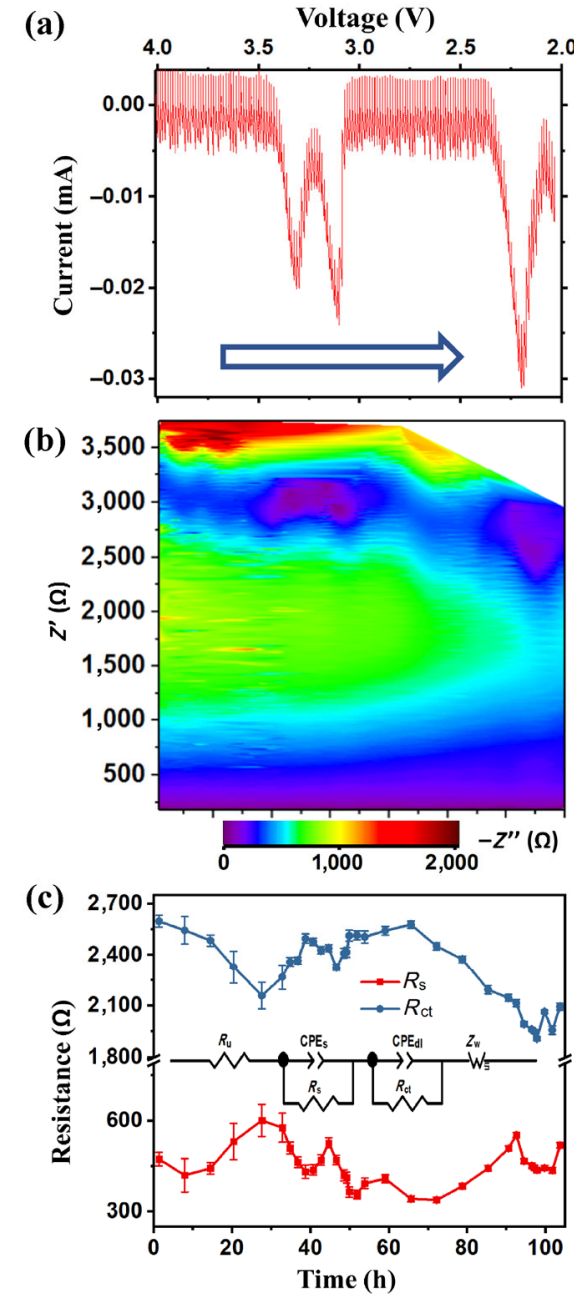

Figure 7 SPEIS tests results during lithium insertion into $\mathrm{V}_{2} \mathrm{O}_{5}$. The $\mathrm{CV}$ (a), in situ EIS (b) and selected fitted EIS results (c).

[28]. The pre-edge peak in Fig. 8(a) shifts to lower energy with the increase of the lithium content in the cathode, which is the result of the reduction in the $\mathrm{V}$ center. At the meantime, the $\mathrm{V}-\mathrm{O}$ around $1.5 \AA$ becomes longer and the length of $\mathrm{V}-\mathrm{V}$ around $\sim 2.8$ is reduced, which can be seen in Fig. 8(b). The $\mathrm{V}-\mathrm{O}$ bond is treated as the skeleton of the crystal and therefore a larger $\mathrm{V}-\mathrm{O}$ bond distance may induce an unstable host at high lithium content $[25,29]$. Even worse, regarding different cycles (Figs. 8(c) and 8(d)), the V-O bond is not only extended but also dispersed (with a broadened peak in Fig. 8(d)), both of which are contributed to a more disordered structure. This result is in good coincidence with the in-situ XRD and in-situ Raman results. All these characterizations above prove that bond changes of $\mathrm{V}-\mathrm{O}$ and $\mathrm{V}-\mathrm{V}$ are closely related to structural degradation and capacity fading of $\mathrm{V}_{2} \mathrm{O}_{5}$ and thus methods modifying/stabilizing atomic coordinates in this material may achieve a continually high capacity. It is worth noting that pre-intercalation of the alkaline or alkaline-earth metal ions is one of the best modification methods in solving this issue during the electrochemical process.

\section{Conclusion}

Capacity fading is one of the hot topics in the battery field. Uncovering the intrinsic reaction mechanism will help understand the origin of the cell malfunction. Here, by combining in situ XRD, in situ Raman and a series of electrochemical tests, the electrochemical (de-)insertion process of $\mathrm{Li}_{x} \mathrm{~V}_{2} \mathrm{O}_{5}(0<x<2)$ is investigated in detail. The in situ XRD and in situ Raman combined with the ex-situ XAFS confirm that the shortest $\mathrm{V}-\mathrm{O}$ and $\mathrm{V}-\mathrm{V}$ bonds variations may 

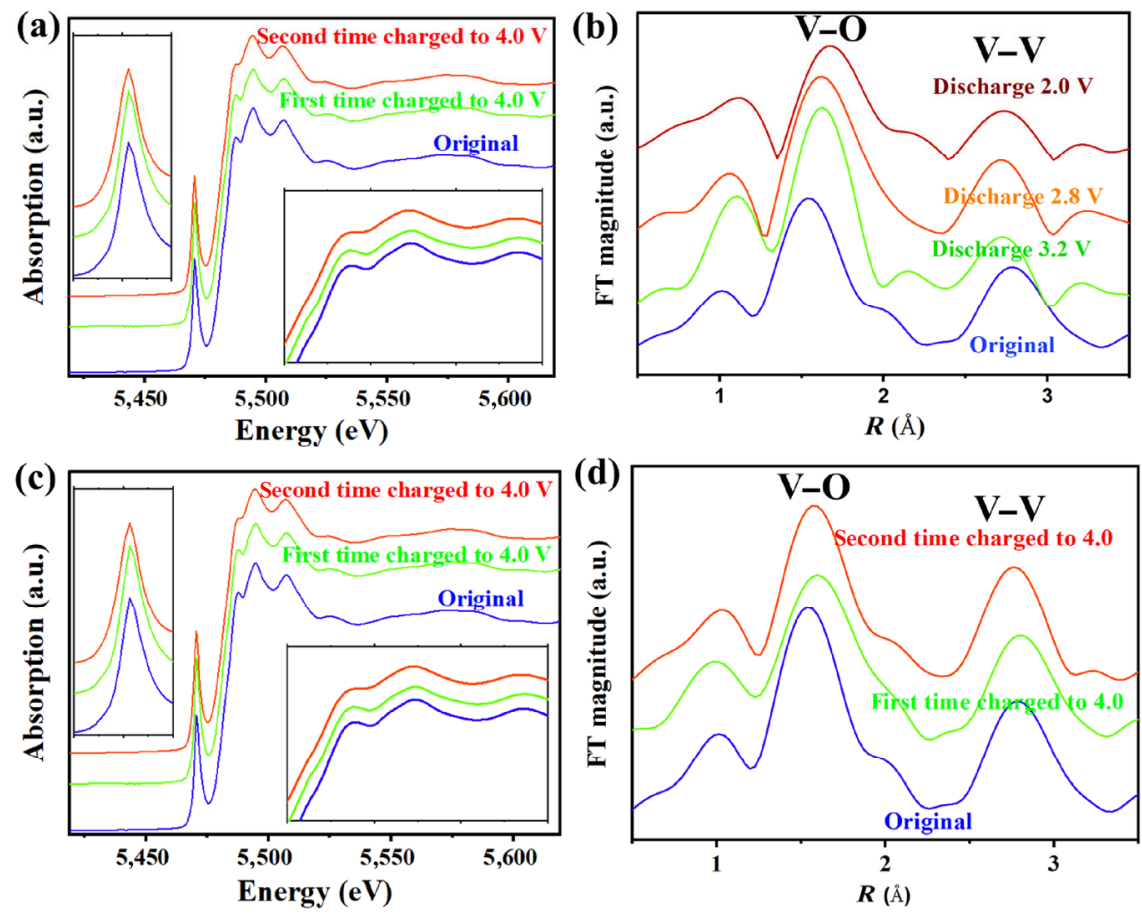

Figure 8 Ex-situ XANES (a) and (c) and Fourier transform of EXAFS (b) and (d) of the V K-edge of $\mathrm{V}_{2} \mathrm{O}_{5}$ at OCV, $3.2 \mathrm{~V}, 2.8 \mathrm{~V}, 2.0 \mathrm{~V}$ and discharged to $2.0 \mathrm{~V}$ then charged to $4.0 \mathrm{~V}$ for the first as well as the second time.

be the origin structural change, which further results in capacity fading. This work also indicates that the metal-oxygen and metalmetal bonds form the skeleton of the crystal structure and by stabilizing the shortest metal-oxygen bond the malfunction process may be retarded.

\section{Acknowledgements}

This work is supported by the National Natural Science Foundation of China (Nos. 51425204, 51832004, 51872218, 51521001, 21805219, and 51302203), the National Key Research and Development Program of China (No. 2016YFA0202603), the Programme of Introducing Talents of Discipline to Universities (No. B17034), the Yellow Crane Talent (Science \& Technology) Program of Wuhan City, the project of innovative group for low cost and long cycle life $\mathrm{Na}$-ion batteries R\&D and Industrialization of Guangdong Province (No. 2014ZT05N013) and the Fundamental Research Funds for the Central Universities (WUT: 2017-YB-005, 2017IVA100, 2017IVA096, 2017 III040). The $\mu$-XRF beam time is granted by $4 \mathrm{~W} 1 \mathrm{~B}$ endstation of Beijing Synchrotron Radiation Facility, Institute of High Energy Physics, Chinese Academy of Sciences. The staff members of 4W1B are acknowledged for their support in measurements and data reduction. Dr. Yunlong Zhao thanks Advanced Technology Institute at University of Surrey and the UK National Measurement System. Guobin Zhang and Prof. Liqiang Mai thank Prof. Yan Zhao for the discussion.

Electronic Supplementary Material: Supplementary material (crystallographic date, XRD patterns, the refined XRD patterns, video images and the fitted Raman intensity decay curve) is available in the online version of this article at https://doi.org/10.1007/s12274-0192321-z.

Open Access This article is licensed under a Creative Commons Attribution 4.0 International License, which permits use, sharing, adaptation, distribution and reproduction in any medium or format, as long as you give appropriate credit to the original author(s) and the source, provide a link to the Creative Commons licence, and indicate if changes were made.

The images or other third party material in this article are included in the article's Creative Commons licence, unless indicated otherwise in a credit line to the material. If material is not included in the article's Creative Commons licence and your intended use is not permitted by statutory regulation or exceeds the permitted use, you will need to obtain permission directly from the copyright holder.

To view a copy of this licence, visit http://creativecommons.org/ licenses/by/4.0/.

\section{References}

[1] Xiang, X. D.; Zhang, K.; Chen, J. Recent advances and prospects of cathode materials for sodium-ion batteries. Adv. Mater. 2015, 27, 5343-5364.

[2] Fang, C.; Huang, Y. H.; Zhang, W. X.; Han, J. T.; Deng, Z.; Cao, Y. L.; Yang, H. X. Routes to high energy cathodes of sodium-ion batteries. $A d v$. Energy Mater. 2016, 6, 1501727.

[3] Xu, Y.; Zhou, M.; Lei, Y. Nanoarchitectured array electrodes for rechargeable lithium- and sodium-ion batteries. Adv. Energy Mater. 2016, 6, 1502514.

[4] Islam, M. S.; Fisher, C. A. J. Lithium and sodium battery cathode materials: Computational insights into voltage, diffusion and nanostructural properties. Chem. Soc. Rev. 2014, 43, 185-204.

[5] Li, L.; Wu, Z.; Yuan, S.; Zhang, X. B. Advances and challenges for flexible energy storage and conversion devices and systems. Energy Environ. Sci. 2014, 7, 2101-2122.

[6] Krahl, T.; Marroquin Winkelmann, F.; Martin, A.; Pinna, N.; Kemnitz, E. Novel synthesis of anhydrous and hydroxylated $\mathrm{CuF}_{2}$ nanoparticles and their potential for lithium ion batteries. Chem.-Eur. J. 2018, 24, 7177-7187.

[7] Kashfi-Sadabad, R.; Yazdani, S.; Huan, T. D.; Cai, Z.; Pettes, M. T. Role of oxygen vacancy defects in the electrocatalytic activity of substoichiometric molybdenum oxide. J. Phys. Chem. C 2018, 122, 18212-18222.

[8] Tian, P.; Song, Q.; Pang, H. C.; Ning, G. L. Hollow microspherical vanadium pentoxide fabricated via non-hydrothermal route for lithium ion batteries. Mater. Lett. 2018, 227, 13-16.

[9] Wu, K.; Zhan, J.; Xu, G.; Zhang, C.; Pan, D. Y.; Wu, M. H. $\mathrm{MoO}_{3}$ nanosheet arrays as superior anode materials for $\mathrm{Li}$ - and $\mathrm{Na}$-ion batteries. Nanoscale 2018, 10, 16040-16049. 
[10] Wan, F.; Zhang, L. L.; Dai, X.; Wang, X. Y.; Niu, Z. Q.; Chen, J. Aqueous rechargeable zinc/sodium vanadate batteries with enhanced performance from simultaneous insertion of dual carriers. Nat. Commun. 2018, 9, 1656.

[11] Dai, X.; Wan, F.; Zhang, L. L.; Cao, H. M.; Niu, Z. Q. Freestanding graphene $/ \mathrm{VO}_{2}$ composite films for highly stable aqueous $\mathrm{Zn}$-ion batteries with superior rate performance. Energy Storage Mater. 2019, 17, 143-150.

[12] Mai, L. Q.; Yan, M. Y.; Zhao, Y. L. Track batteries degrading in real time. Nature 2017, 546, 469-470.

[13] Zhang, G. B.; Xiong, T. F.; He, L.; Yan, M. Y.; Zhao, K. N.; Xu, X.; Mai, L. $\mathrm{Q}$. Electrochemical in situ X-ray probing in lithium-ion and sodium-ion batteries. J. Mater. Sci. 2017, 52, 3697-3718.

[14] Zhang, G. B.; Xiong, T. F.; Yan, M. Y.; He, L.; Liao, X. B.; He, C. Q.; Yin, C. S.; Zhang, H. N.; Mai, L. Q. $\alpha-\mathrm{MoO}_{3-x}$ by plasma etching with improved capacity and stabilized structure for lithium storage. Nano Energy 2018, 49, 555-563.

[15] Wang, H.; Isobe, J.; Matsumura, D.; Yoshikawa, H. In situ X-ray absorption fine structure studies of amorphous and crystalline polyoxovanadate cluster cathodes for lithium batteries. J. Solid State Electrochem. 2018, 22, 2067-2071.

[16] Liu, D. W.; Liu, Y. Y.; Garcia, B. B.; Zhang, Q. F.; Pan, A. Q.; Jeong, Y. H.; Cao, G. Z. $\mathrm{V}_{2} \mathrm{O}_{5}$ xerogel electrodes with much enhanced lithium-ion intercalation properties with $\mathrm{N}_{2}$ annealing. J. Mater. Chem. 2009, 19, 8789-8795.

[17] Li, Y. W.; Yao, J. H.; Uchaker, E.; Yang, J. W.; Huang, Y. X.; Zhang, M.; Cao, G. Z. Leaf-like $\mathrm{V}_{2} \mathrm{O}_{5}$ nanosheets fabricated by a facile green approach as high energy cathode material for lithium-ion batteries. Adv. Energy Mater. 2013, 3, 1171-1175.

[18] Murphy, D. W.; Christian, P. A.; DiSalvo, F. J.; Waszczak, J. V. Lithium incorporation by vanadium pentoxide. Inorg. Chem. 1979, 18, 2800-2803.

[19] Cocciantelli, J. M.; Doumerc, J. P.; Pouchard, M.; Broussely, M.; Labat, J. Crystal chemistry of electrochemically inserted $\mathrm{Li}_{x} \mathrm{~V}_{2} \mathrm{O}_{5}$. J. Power Sources 1991, 34, 103-111.

[20] Delmas, C.; Cognac-Auradou, H.; Cocciantelli, J. M.; Ménétrier, M.; Doumerc, J. P. The $\mathrm{Li}_{x} \mathrm{~V}_{2} \mathrm{O}_{5}$ system: An overview of the structure modifications induced by the lithium intercalation. Solid State Ionics 1994, 69, 257-264.
[21] Baddour-Hadjean, R.; Golabkan, V.; Pereira-Ramos, J. P.; Mantoux, A.; Lincot, D. A Raman study of the lithium insertion process in vanadium pentoxide thin films deposited by atomic layer deposition. J. Raman Spectrosc. 2002, 33, 631-638.

[22] Baddour-Hadjean, R.; Navone, C.; Pereira-Ramos, J. P. In situ Raman microspectrometry investigation of electrochemical lithium intercalation into sputtered crystalline $\mathrm{V}_{2} \mathrm{O}_{5}$ thin films. Electrochim. Acta 2009, 54, 6674-6679.

[23] Mansour, A. N.; Smith, P. H.; Baker, W. M.; Balasubramanian, M.; McBreen, J. A comparative in situ X-ray absorption spectroscopy study of nanophase $\mathrm{V}_{2} \mathrm{O}_{5}$ aerogel and ambigel cathodes. J. Electrochem. Soc. 2003, 150, A403-A413.

[24] Armstrong, E.; McNulty, D.; Geaney, H.; O’Dwyer, C. Electrodeposited structurally stable $\mathrm{V}_{2} \mathrm{O}_{5}$ inverse opal networks as high performance thin film lithium batteries. ACS Appl. Mater. Interfaces 2015, 7, 27006-27015.

[25] Lu, Y. R.; Wu, T. Z.; Chen, C. L.; Wei, D. H.; Chen, J. L.; Chou, W. C.; Dong, C. L. Mechanism of electrochemical deposition and coloration of electrochromic $\mathrm{V}_{2} \mathrm{O}_{5}$ nano thin films: An in situ X-ray spectroscopy study. Nanoscale Res. Lett. 2015, 10, 387.

[26] Burba, C. M.; Frech, R. Modified coin cells for in situ Raman spectroelectrochemical measurements of $\mathrm{Li}_{x} \mathrm{~V}_{2} \mathrm{O}_{5}$ for lithium rechargeable batteries. Appl. Spectrosc. 2006, 60, 490-493.

[27] Zhou, L. L.; Shen, S. Y.; Peng, X. X.; Wu, L. N.; Wang, Q.; Shen, C. H.; Tu, T. T.; Huang, L.; Li, J. T.; Sun, S. G. New insights into the structure changes and interface properties of $\mathrm{Li}_{3} \mathrm{VO}_{4}$ anode for lithium-ion batteries during the initial cycle by in-situ techniques. ACS Appl. Mater. Interfaces 2016, 8, 23739-23745.

[28] Ravel, B.; Newville, M. ATHENA, ARTEMIS, HEPHAESTUS: Data analysis for X-ray absorption spectroscopy using IFEFFIT. J. Synchrotron Radiat. 2005, 12, 537-541.

[29] Giorgetti, M.; Passerini, S.; Smyrl, W. H.; Mukerjee, S.; Yang, X. Q.; McBreen. In situ X-ray absorption spectroscopy characterization of $\mathrm{V}_{2} \mathrm{O}_{5}$ xerogel cathodes upon lithium intercalation. J. Electrochem. Soc. 1999, $146,2387-2392$ 